\title{
EFFICIENT DETERMINATION OF HELIPORTS IN THE CITY OF RIO DE JANEIRO FOR THE OLYMPIC GAMES AND WORLD CUP: A FUZZY LOGIC APPROACH
}

\author{
Claudio S. Bisso \\ Universidade Federal do Rio de Janeiro - COPPE \\ Programa de Engenharia de Produção, Centro de Tecnologia, Bloco F, sala 105, Cidade Universitária, \\ Rio de Janeiro, Brasil. \\ Cbisso42@gmail.com \\ Carlos P. Samanez \\ Pontifícia Universidade Católica do Rio de Janeiro - PUC-Rio \\ Departamento de Engenharia Industrial, Rua Marques de S. Vicente, 225, Gávea, Rio de Janeiro, \\ Brasil. \\ cps@puc-rio.br
}

\begin{abstract}
RESUMO
O objetivo desse trabalho é determinar um método que permita avaliar as Zonas de Pouso de Helicóptero (ZPH) que justifiquem investimento para sua adaptação aos requisitos previstos para helipontos de uso público registrados visando os Jogos Olímpicos e a Copa do Mundo. A metodologia utilizou duas etapas, a primeira através da clusterização dos dados obtidos através do GAM/PMERJ e a segunda através da aplicação do método de ranqueamento ponderado. O Método de ranqueamento ponderado aplica-se para a seleção de locais através da utilização da lógica fuzzy, utilizando variáveis lingüísticas e uma direta avaliação das alternativas. Baseado na seleção de quatro clusters, foram obtidas oito ZPH's para serem ranqueadas. A metodologia proposta por este trabalho permite uma integração entre a malha aérea utilizada pelos órgãos de defesa e assistência do Estado com as locações onde serão realizados os eventos esportivos de 2014 e 2016.
\end{abstract}

PALAVARAS CHAVE. Lógica Fuzzy, Localização, Transporte, Políticas Públicas.

Área principal: LT - Logística e Transportes; MC - Métodos de Apoio a Decisão Multicritério

\begin{abstract}
The purpose of this study was to determine a method of evaluation for the use and adaptation of Helicopter Landing Zones (HLZs) and their requirements for registered public-use for the Olympic Games and the World Cup. The proposed method involves two stages. The first stage consists of clustering the data obtained through the Aerial and Maritime Group/Military Police of the State of Rio de Janeiro (GAM/PMERJ). The second stage uses the weighted ranking method. The weighted ranking method was applied to a selection of locations using fuzzy logic, linguistic variables and a direct evaluation of the alternatives. Based upon the selection of four clusters, eight HLZs were obtained for ranking. The proposed method may be used to integrate the air space that will be used by the defense and state assistance agencies with the locations of the sporting events to be held in 2014 and 2016.
\end{abstract}

KEYWORDS. Fuzzy logic, Site selection, Transport, Public Policy.

Main area: LT - Logistics and Transport; MC - Multi-criteria Decision Methods 


\section{INTRODUCTION}

The city of Rio de Janeiro will host the 2014 World Cup and 2016 Olympic competitions. Thus, the development of more effective and technical mapping is urgently needed to rationalize the use of aerial resources (helicopters) that belong to the state of Rio de Janeiro. Consequently, the helicopters will meet the demands for human health and safety better, as well as actively participate in these large sporting events.

The main objective of this study was to determine a method that could be used to justify potential investment opportunities in registered public-use heliports based on their requirements and their locations relative to points of public interest. To accomplish this task, Helicopter Landing Zones, or HLZs, were mapped and identified by the Aerial and Maritime Group (Grupamento Aéreo e Marítimo (GAM)) of the Military Police of the State of Rio de Janeiro (Polícia Militar do Estado do Rio de Janeiro (PMERJ)).

In the city of Rio de Janeiro, various zones were identified by the GAM as HLZs. Yet, these zones do not have the appropriate identification, illumination or signage. Thus, these HLZs do not meet the appropriate technical standards that would define them as zones being appropriate for helicopter landing. Here, several aspects, including the proximity of the HLZs to hospitals, PMERJ (Military Police of the State of Rio de Janeiro) units, Fire Department (CBMERJ), Civil Police (PCERJ) and the major sporting competition locations, were used to identify the most relevant HLZs in the city of Rio de Janeiro (according to these criteria). In addition, this study serves to stimulate the use of the HLZs and provide subsidies for developing public policies for streamlining the existing aerial resources (helicopters) that belong to corporations within the state of Rio de Janeiro.

Today, Rio de Janeiro faces a challenge that it has never face before. The burden of investments in various sectors - led by the oil and gas industry - sum, according to the Federation of Industries of the State of Rio de Janeiro (FIRJAN), \$ 76 billion during the period from 2011 to 2013. This is one of the largest concentrations of investment in the world, given the volume of investments in relation to the small territorial dimension of the state.

Air transport demand brought by those investments, combined with the fact that the city will host the 2014 World Cup and the 2016 Olympic Games, requires a focused technical mapping that allows streamlining the aerial resources (helicopter) and the helicopter landing zones (HLZ). In this sense, the present study contributes by showing a method that identifies and assesses those HLZs, justifying public and/or private investment in adaptation, reform and creation of helipads in the city of Rio de Janeiro.

\section{ORIGIN OF THE DATA}

The data that was used for choosing the locations for implementing the heliports for public use in Rio de Janeiro was obtained from a database that was prepared by the GAM of the PMERJ (GAM/PMERJ 2010-2016 Multi-year plan, 2009). The GAM identified existing, viable Helicopter Landing Zones (HLZs) based on the helicopter flights over Rio de Janeiro. These HLZs include soccer fields, parking areas, unsheltered areas, unregistered heliports and locations where helicopter landing is feasible.

The quality of these HLZs was based upon how closely they met the predicted 
standard requirements for becoming a registered heliport. Overall, the quality of the HLZs was highly variable. Although several HLZs met all of the requirements, others were extremely restricted by obstacles, such as high buildings, trees, posts, and electrical transmission lines.

In addition to the HLZs, the database provided by the GAM contains the hospitals of interest and the PMERJ, CBMERJ and PCERJ units in separate spreadsheets. The locations of the major sporting competitions were obtained by consulting the GAM/PMERJ 2010-2016 Multi-year Plan and were mapped by the authors with the Google Earth ${ }^{\circledR}$ software. A succinct description of these data is provided in Table 1.

Table 1: Data description

\begin{tabular}{l|l}
\hline Category & Quantity \\
\hline Helicopter landing zones & 436 \\
Hospitals & 10 \\
Fire Department (CBMERJ & 63 \\
Military Police (PMERJ) & 76 \\
Civil Police (PCERJ) & 14 \\
Sport events location & 18 \\
\hline TOTAL & 617 \\
\hline
\end{tabular}

\section{BIBLIOGRAPHIC REVIEW}

Several approaches have been reported in the literature for solving location problems (Aikens, 1985; Hamacher \& Nickel, 1998). Agrawal, 2010, presents a hybrid approach, using the features of the Taguchi technique with Artificial Immune Systems (AIS), to optimize an integrated supply chain design problem with multiple shipping. Sun et al. (2008), present a bilevel programming model for the location of logistics distribution centers. Multi-criteria facility location models have been investigated by researchers in Lee et al., 1981 and Ross \& Soland, 1980.

It is worth noting that most of the works mentioned above study the location problem within a certain environment, in other words, the parameters in the problem are fixed and known in advance.

To deal with parameters that cannot be obtained with certainty, location problems have been extensively studied in the literature by using multi-criteria decisions, fuzzy logic methods and other mathematical tools (Chi \& Kuo, 2001). The majority of these models seek to maximize revenue or to minimize expenses. In addition, the majority of these approaches only provide systematic procedures for resolving the problem without considering the global aspects that can affect the system, such as decision-making factors (Chen \& Qu, 2006).

It is important to introduce "uncertainties" in the ratings and weights of various factors that are associated with determining locations. Uncertainty emerges primarily from a lack of precise or reliable information and from the need to evaluate a series of factors that are frequently intangible. Regarding the application of fuzzy logic, Terano (1992) states, "the 
preeminent characteristic of the fuzzy sets is the ability to express the quantity of ambiguity present in human thought and the subjectivity (including natural language) in a manner relatively free from distortions".

The Fuzzy Sets Theory was introduced by Zadeh (1965) to handle a problem with ambiguity. Thus, linguistic values could be used to approximate rationale based on the fuzzy sets theory to handle data evaluation ambiguity effectively. Regarding the vague properties of the linguistic expressions, normal triangular fuzzy numbers were used to characterize the fuzzy values of the quantitative data and linguistic terms that were used in the approximate rationale (Lee, 1996 and Zadeh, 1975). Ambiguity is one characteristic of human thought. The Fuzzy Sets Theory is an effective tool for incorporating subjectivity into decision-making processes (Wei et al., 2008)

Narasimhan (1979) applied fuzzy subsets to a problem that involved selecting gas station locations by proposing a model with linguistic variables and by directly evaluating feasible alternatives with fuzzy variables.

Additionally, Narasimhan (1979) aimed to define the degree of preference when dealing with unreliable and imprecise information based on conversations with decision makers. Thus, this method consisted of two criteria, including scenario criteria (which seek to filter and remove locations that do not meet the essential requirements as indicated by the decision makers) and evaluation criteria (which seek to evaluate the selected locations).

This modeling was suggested by Narasimhan and was used here due to its simplicity and potential for assigning numbers to rate each factor associated with a location.

\section{APPLICATION}

This study was conducted in two stages. The first stage involved the use of a clustering method and the second stage involved the application of a weighted ranking method (described by Narasimhan (1979)).

Clustering was used to group the data (the HLZs and locations of public interest) and to select the clusters that contain both HLZs and locations of public interest. Clusters that contained only HLZs were discarded and clusters that contained only points of public interest were used to represent areas with large concentrations of public resources without current helicopter access.

In addition, due to the size of the problem- the large number of HLZs and locations of public interest that were selected by the GAM- clustering was used to delimit the original data, which restricted analysis to a simpler sub-problem. This delimitation was performed by selecting points that were contained in a few clusters with specific characteristics.

The weighted ranking method from Narasimhan (1979) was used to define preferential HLZs based on the ease of terrestrial access to the points of interest. The ease of terrestrial access to these sites is important because the HLZs that do not have easy terrestrial access, or any type of possible access, are not suitable for loading and unloading people or the general population.

The location analyses for this problem have frequently concentrated on accessibility and on the impacts of activities through the application of accessibility indicators. Accessibility is defined as "the relative proximity of one place to another" (Tsou et al., 2005). 
The concept of accessibility is used to explain the availability of one product, device, service or environment.

In addition, the degree of relative importance between points of interest was also considered. In this case, different weights were used do define the ease of access for each type of point of interest.

\subsection{CLUSTERING AND COMPUTATIONAL RESOURCES}

The geographical coordinates for all of the points (HLZs and locations of interest) were obtained in decimal coordinates using the Google Earth ${ }^{\circledR}$ software. In addition, the R statistical and data mining software (version 2.11.1) was used with the editor/compiler of the $\mathrm{R} \AA$ language (Tinn- $\mathrm{R}$, version 2.3.7.0).

The simple K-means clustering method (MacQueen, 1967) was used in this study. The K-means method is potentially one of the most intuitive clustering methods. In this method, each object belongs to only one cluster, and all of the clusters contain at least one element.

Various configurations were considered for clustering (that is, various numbers of centroids) in the K-means algorithm. The results from these configurations are discussed in the results section. The Euclidean distance was used to measure the distance between the points. The Euclidean distance between two points $a=(a x, a y)$ and $b=(b x, b y)$ is defined as:

$$
d(a, b)=\sqrt{\left(a_{x} \square b_{x}\right)^{2}+\left(a_{y} \square b_{y}\right)^{2}}
$$

The first step of the algorithm is initialization. During initialization, the clusters for each element are determined. Usually, this can be accomplished in two different ways. In the first method, one of the centers of each cluster is chosen randomly within the elements. In the second method, each object is placed in a random cluster before calculating the centers. The centers are recalculated at each iteration when the elements are reallocated between the clusters to optimize the cost function with an iterative procedure (Luenberger, 1984).

Let $\mathrm{x}_{\mathrm{i}}$ represent the objects to be clustered. By considering the objects as vectors, the center $v_{j}$ of cluster $C_{j}$ can be calculated as the average of all of the elements in the cluster as follows:

$$
v_{j}=\frac{1}{\left|C_{j}\right|} \square_{\square x_{i} \square C_{j}} x_{i}
$$

From this equation, the distance $D_{i j}$ from each element $\mathrm{x}_{\mathrm{i}}$ to each center $\mathrm{v}_{\mathrm{j}}$ is calculated. Usually, the Euclidean distance is used.

From these distances, each element is reallocated to the closest cluster (based on the cluster center). Next, it is determined if more iterations are needed. The criteria are simple. While changes are occurring, new centers are calculated and the objects are reallocated. When no more changes are occurring, the algorithm stops. 


\subsection{WEIGHTED RANKING METHOD}

The weighted ranking method was applied to a selection of locations using fuzzy logic. To apply the model proposed in this study, the HLZs (known as $\mathbf{L}_{\mathbf{1}}, \mathbf{L}_{\mathbf{2}} \ldots \mathbf{L}_{\mathbf{n}}$ ) were considered as locations to be selected.

For each location $\mathbf{L}_{\mathbf{i}}$, five attributes, $\mathbf{a}_{1}, \mathbf{a}_{2}, \mathbf{a}_{3}, \mathbf{a}_{4}$ and $\mathbf{a}_{5}$, were used. These attributes represented the ease of access to the hospitals, PMERJ units, CBMERJ units, PCERJ units and major sporting competition locations, respectively (Table 2). The accessibility attributes were chosen to grant air space integration between the defense and state assistance agencies and the locations of the sporting events.

Table 2: Accessibility attributes of the HLZ

\begin{tabular}{c|l}
\hline \multicolumn{2}{c}{ Attributes } \\
\hline $\mathrm{a}_{1}$ & Ease of access to hospitals or health care facilities \\
$\mathrm{a}_{2}$ & Ease of access to Military Police (PMERJ) units \\
$\mathrm{a}_{3}$ & Ease of access to firefighter (CBMERJ) units \\
$\mathrm{a}_{4}$ & Ease of access to Civil Police (PCERJ) units \\
$\mathrm{a}_{5}$ & Ease of access to sport events locations \\
\hline
\end{tabular}

The value of each attribute $\mathbf{a}_{\mathbf{i}}$ for location $\mathbf{L}_{\mathbf{j}}$ was represented by the fuzzy variable $\mathbf{r}_{\mathbf{i j}}$. Five linguistic values were attributed to these fuzzy variables. One of these variables used the modifier "very" $\mathbf{r}_{\mathbf{i j}}$ \{very easy, easy, average, difficult, and not feasible\}.

To decrease the variability of the linguistic values $\mathbf{r}_{\mathbf{i j}}$ that were attributed by the evaluators to the attributes ai from the locations $\mathbf{L}_{\mathbf{j}}$, a table was created to explain the meaning of the linguistic values relative to the attributes. These values are shown in Table 3.

Table 3: Linguistic values meanings $\left(\mathrm{r}_{\mathrm{ij}}\right)$

\begin{tabular}{l|l}
\hline Linguistic value & \multicolumn{1}{c}{ Meaning } \\
\hline$\square$ Very easy & $\square$ HLZ within or adjacent to the site of interest. \\
$\square$ Easy & $\square$ HLZ close to the site of interest, with good quality access, easy \\
traffic throughout the day. \\
$\square$ Average & $\square$ HLZ in an average distance to the site of interest, with \\
reasonable quality pathway access, possibility of some traffic. \\
$\square$ Difficult & $\square$ HLZ far from the site of interest, with poor quality, many road \\
traffic lights or intersections, possibility of bad traffic. \\
$\square$ Not feasible & $\square$ It is not possible to consider ground transportation between \\
HLZ considered and the site of interest.
\end{tabular}

Each linguistic value was represented with triangular fuzzy numbers by the authors (Table 4). These values were chosen to represent the authors' consensus with the best reliability 
Table 4: Linguistic values $\mathrm{r}_{\mathrm{ij}}$

\begin{tabular}{l|c}
\hline \multicolumn{2}{c}{ Triangular fuzzy numbers for the linguistic values $\mathbf{r}_{\mathbf{i j}}$} \\
\hline Very easy & $(0.7,0.9,0.9)$ \\
Easy & $(0.5,0.7,0.9)$ \\
Average & $(0.3,0.5,0.7)$ \\
Difficult & $(0.1,0.3,0.5)$ \\
Not feasible & $(0.1,0.1,0.3)$ \\
\hline
\end{tabular}

To allow for the compositions of the various $\mathbf{r}_{\mathbf{i j}}$ values that the evaluators attributed to each attribute $\mathbf{a}_{\mathbf{i}}$ from the locations $\mathbf{L}_{\mathbf{j}}$, weights were assigned to quantify the relative importance between the $\mathbf{a}_{\mathbf{i}}$ attributes (with $\mathbf{W}_{\mathbf{j}}$ as the weight associated with the attribute $\mathbf{a}_{\mathbf{i}}$ ).

The weight $\mathbf{W}_{\mathbf{j}}$ was defined as a fuzzy linguistic variable. Four linguistic values were attributed to this variable. One of these values used the modifier "very" and another used the modifier "less" as follows:

$$
\mathbf{W}_{\mathbf{j}} \text { \{very important, important, average, less important }
$$

The triangular fuzzy numbers that represent the linguistic values of $\mathbf{W}_{\mathbf{j}}$ are shown in Table 5.

Table 5: Linguistic values $\mathrm{W}_{\mathrm{i}}$

\begin{tabular}{l|c}
\hline \multicolumn{2}{c}{ Triangular fuzzy numbers for $\mathbf{W}_{\mathbf{j}}$} \\
\hline Very important & $(0.75,1.0,1.0)$ \\
Important & $(0.5,0.75,1.0)$ \\
Average & $(0.25,0.5,0.75)$ \\
Less important & $(0.0,0.25,0.5)$ \\
\hline
\end{tabular}

Finally, the problem structure was established as shown in Table 6 and was similar to the problem structure proposed by Narasimhan (1979).

Table 6: Problem structure. Adapted from Narasimhan, 1979.

\begin{tabular}{|c|c|c|c|c|c|c|}
\hline & $\mathrm{L}_{1}$ & $\mathrm{~L}_{2}$ & $\mathrm{~L}_{3}$ & 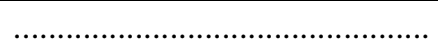 & $\mathrm{L}_{\mathrm{n}}$ \\
\hline $\mathrm{a}_{1}$ & $\mathrm{~W}_{1}$ & $\mathrm{r}_{11}$ & $r_{12}$ & $\mathrm{r}_{13}$ & & $\mathrm{r}_{1 \mathrm{n}}$ \\
\hline$a_{2}$ & $\mathrm{~W}_{2}$ & $\mathrm{r}_{21}$ & $r_{22}$ & $\mathrm{r}_{23}$ & & $r_{2 n}$ \\
\hline$a_{3}$ & $\mathrm{~W}_{3}$ & $r_{31}$ & $r_{32}$ & $r_{33}$ & $r_{i j}$ & $r_{3 n}$ \\
\hline $\mathrm{a}_{4}$ & $\mathrm{~W}_{4}$ & $\mathrm{r}_{41}$ & $r_{42}$ & $r_{43}$ & & $r_{4 n}$ \\
\hline$a_{5}$ & $\mathrm{~W}_{5}$ & $\mathrm{r}_{51}$ & $r_{52}$ & $r_{53}$ & & $r_{5 n}$ \\
\hline
\end{tabular}

To classify the HLZs in a way that permits the visualization of the relative suitability 
of each HLZ relative to its location near a point of interest (by respecting the relative weights between their various types and indicating the HLZs that best serve the points of interest), the coefficient $\overline{r_{i}}$ was determined as follows:

$$
\overline{r_{i}}=\frac{\prod_{j=1}^{5} W_{j} r_{i j}}{\prod_{j=1}^{5} W_{j}} .
$$

Where the coefficient $\overline{r_{i}}$ from the point $L_{i}$ is given by equation (3) based on fuzzy operations.

$$
\bar{r}_{i}=\frac{W_{1} r_{i 1} \square W_{2} r_{i 2} \square W_{3} r_{i 3} \square W_{4} r_{i 4} \square W_{5} r_{i 5}}{W_{1} \square W_{2} \square W_{3} \square W_{4} \square W_{5}}
$$

From the $\bar{r}_{i}$ coefficients related to each of the HLZs, the coefficient $p_{i}$ was calculated (named the normalized general rating (Narasimhan, 1979)) for the alternative location $i$.

$$
p_{i}=\bar{r}_{i}-\frac{1}{n-1} \prod_{\substack{k=1 \\ k \square i}}^{m} \bar{r}_{k}
$$

The definitions of the attribute weights and the degrees of non-quantitative weighting for each linguistic variable and for each attribute are determined through a consensus process that applies the Delphi Technique (Pill, 1971) to all of the decision makers that are involved in the process. Thus, this method is based on information from key people in the decisionmaking process and aims for quality. In addition, the largest possible consensus is gained by weighting this treatment (Levine, 1984). However, in the absence of a consistent scheme for resolving the uncertainty in the location evaluations, methods based on judgment and experience can subsidize a non-optimal choice or accepted location.

\section{RESULTS}

\subsection{CLUSTERING RESULTS}

The clusters obtained from the $\mathrm{R}{ }^{\circledR}$ software represent a geographical agglomeration of points (HLZs and locations of interest). However, the geographical proximity does not indicate that an HLZ will serve as a transport terminal for a point of interest.

An HLZ positioned on an island near the continent can be geographically closer to a point of interest on the coast than another HLZ on the continent. However, if no connecting bridge is present between the island and the point of interest, the more distant HLZ may serve the point of interest better than the closer HLZ.

In order to avoid a comparison between distant points that would produce useless results, the obtained clusters served as a starting point for the analysis of the points that 
belonged to the same cluster. When more than one location of public interest of the same nature was found in the same cluster, only the best access was used to define the values attributed to each HLZ.

Clusterings with 50, 80, 90, 100 and 124 clusters were attempted. Clusterings that contained 50, 80 and 90 clusters with many HLZs and only a few public interest locations were obtained. By using a larger number of clusters, a better balance was achieved between the number of HLZs and these locations. In addition, based on the data bank characteristics, a larger number of clusters permitted the neglect of a portion of the HLZs. This result occurred because a larger number of clusters were formed by these landing zones, which were not important for this study.

Finally, clusterings with 100 or more clusters provided the lowest sum of quadratic distances from the points in each cluster to their respective centroids.

Thus, a clustering of 124 clusters was selected as the best tradeoff between the number of clusters (and the number of HLZs per cluster) and the variability of the categories involved in the clusters (that is, an appropriate variety of public interest locations together with few HLZs per cluster).

As previously mentioned, due to the size of the initial problem (the original databank had more than 500 HLZ locations), it was necessary to restrict its scope to a smaller and simpler sub-problem. This restriction was necessary to illustrate the application of the proposed method. In addition, the inclusion of all of the determined clusters is proposed for future studies.

The four selected clusters united some interesting characteristics for illustrating the proposed methodology. For example,

$\square$ They represented diverse public interest locations,

They had a relatively balanced number of public interest locations and HLZs, and They did not have large numbers of HLZs.

Table 7 shows the selected clusters and the categories to which the points contained in these clusters belong.

Table 7: Selected clusters

\begin{tabular}{cccc}
\hline Latitude & Longitude & Code & Cluster number \\
\hline$-22,92673$ & $-43,23783$ & CBM 48 & 9 \\
$-22,92755$ & $-43,25243$ & HPT 3 & 9 \\
$-22,92547$ & $-43,24368$ & PMR 65 & 9 \\
$-22,92467$ & $-43,23779$ & HLZ_173 & 9 \\
$-22,92033$ & $-43,24606$ & HLZ 94 & 9 \\
$-22,90725$ & $-43,22837$ & CBM 28 & 11 \\
$-22,91329$ & $-43,23116$ & CBM_49 & 11 \\
$-22,91043$ & $-43,24149$ & CBM 9 & 11 \\
$-22,91311$ & $-43,22897$ & OLP 9 & 11 \\
$-22,91381$ & $-43,22982$ & PMR_52 & 11 \\
$-22,91763$ & $-43,22904$ & HLZ 92 & 11 \\
$-22,90929$ & $-43,22724$ & HLZ 96 & 11 \\
$-22,90919$ & $-43,18756$ & CBM_29 & 44
\end{tabular}




\begin{tabular}{cccc}
$-22,90857$ & $-43,19008$ & HPT_4 & 44 \\
$-22,90777$ & $-43,18359$ & PMR_67 & 44 \\
$-22,91012$ & $-43,18443$ & HLZ 449 & 44 \\
$-22,93378$ & $-43,17973$ & CBM_30 & 68 \\
$-22,92741$ & $-43,18481$ & OLP_8 & 68 \\
$-22,92826$ & $-43,18401$ & PMR 43 & 68 \\
$-22,93056$ & $-43,18510$ & HLZ_185 & 68 \\
$-22,92823$ & $-43,18379$ & HLZ_458 & 68 \\
$-22,93027$ & $-43,18544$ & HLZ 499 & 68 \\
\hline
\end{tabular}

The first and second columns of Table 7 refer to the latitude and longitude of the points in decimal coordinates, respectively. The third column shows the descriptive codes for the selected points. These codes are formed by two components. The first component is formed by three literal characters that represent a category in which a point belongs (CBM, representing the fire department; PMR representing Military Police battalions, OLP representing points that will host sporting events; HLZ representing helicopter landing zones and HPT representing hospitals).

The selected clusters did not contain any Civil Police units. This finding resulted from the small quantity of locations that were mapped by the GAM. In addition, during the evaluation of the points, it was determined that HLZ 449 was within a Civil Police unit. Thus, this datum was considered in the evaluation as proposed in the method.

\subsection{RESULTS FROM THE APPLICATION OF THE WEIGHTED RANKING METHOD}

Based on the selection of the four previously mentioned clusters, eight HLZs were ranked by the adopted method. Based on this method, the normalized general ratings $\overline{r_{i}}$, the ratings $\bar{r}_{k}$ and the preferability indices $p_{i}$ were calculated. Table 8 illustrates these indices for each of the eight considered helicopter-landing zones.

Table 8: $p_{i}$ preferability indices

\begin{tabular}{ll}
\hline $\mathrm{p}_{1}$ & $(-1,3388 ;-0,1407 ; 1,0194)$ \\
$\mathrm{p}_{2}$ & $(-1,2407 ; 0,0000 ; 1,3028)$ \\
$\mathrm{p}_{3}$ & $(-1,1614 ; 0,1758 ; 1,5346)$ \\
$\mathrm{p}_{4}$ & $(-1,3081 ;-0,0703 ; 1,0728)$ \\
$\mathrm{p}_{5}$ & $(-1,2325 ; 0,0352 ; 1,2795)$ \\
$\mathrm{p}_{6}$ & $(-1,2407 ; 0,0000 ; 1,3028)$ \\
$\mathrm{p}_{7}$ & $(-1,2549 ; 0,0000 ; 1,2028)$ \\
$\mathrm{p}_{8}$ & $(-1,2407 ; 0,0000 ; 1,3028)$ \\
\hline
\end{tabular}

In Table 8, a tie between the preferability indices of $\mathrm{p}_{6}$ and $\mathrm{p}_{8}$ was observed. This result was explained by the physical proximity between the points, which resulted in equal attributes. Regarding the $\mathrm{p}_{2}$ and $\mathrm{p}_{6}$ indices, the equal values resulted from their similar characteristics, which determined the coincidence of the attribute linguistic values. 
The preferability index $p_{i}$ of the eight analyzed HLZs were plotted in the graphical form of triangular fuzzy numbers (Figure 1).

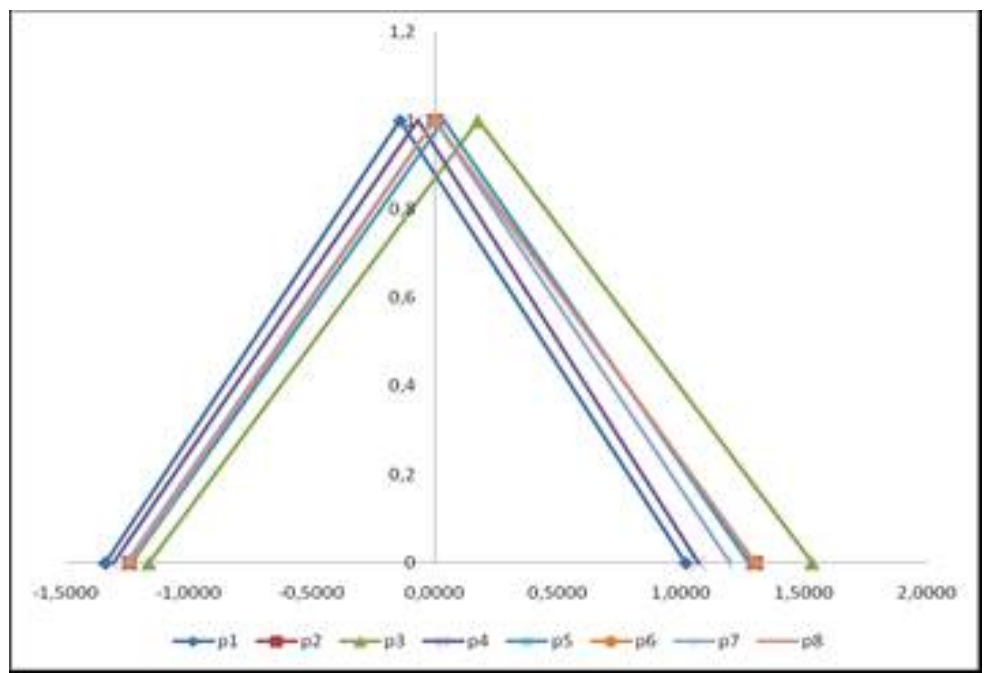

Figure 1: Fuzzy triangular numbers graphic represents the preferability indices.

The $\mathrm{p}_{3}$ index, which refers to the location of HLZ 449, contained in cluster 44, has the greatest degree of preferability (Figure 1). This finding was justified by the fact that its pertinence function resulted in the largest area under the curve in the positive ranges of its support. In addition, the value of the support that corresponded to the maximum pertinence function was furthest from the origin relative to the other maximum points of the other locations.

According to this logic, the decreasing ranking of the considered HLZs is established as follows: $\mathrm{p}_{3}$ (HLZ 449), $\mathrm{p}_{5}$ (HLZ 173), $\mathrm{p}_{2}$ (HLZ 96) / $\mathrm{p}_{6}$ (HLZ 185) / $\mathrm{p}_{8}$ (HLZ 499), $\mathrm{p}_{7}$ (HLZ 458), $\mathrm{p}_{4}$ (HLZ 94) and $\mathrm{p}_{1}$ (HLZ 92).

The four clusters with their respective points can be observed geographically in Figure 2.

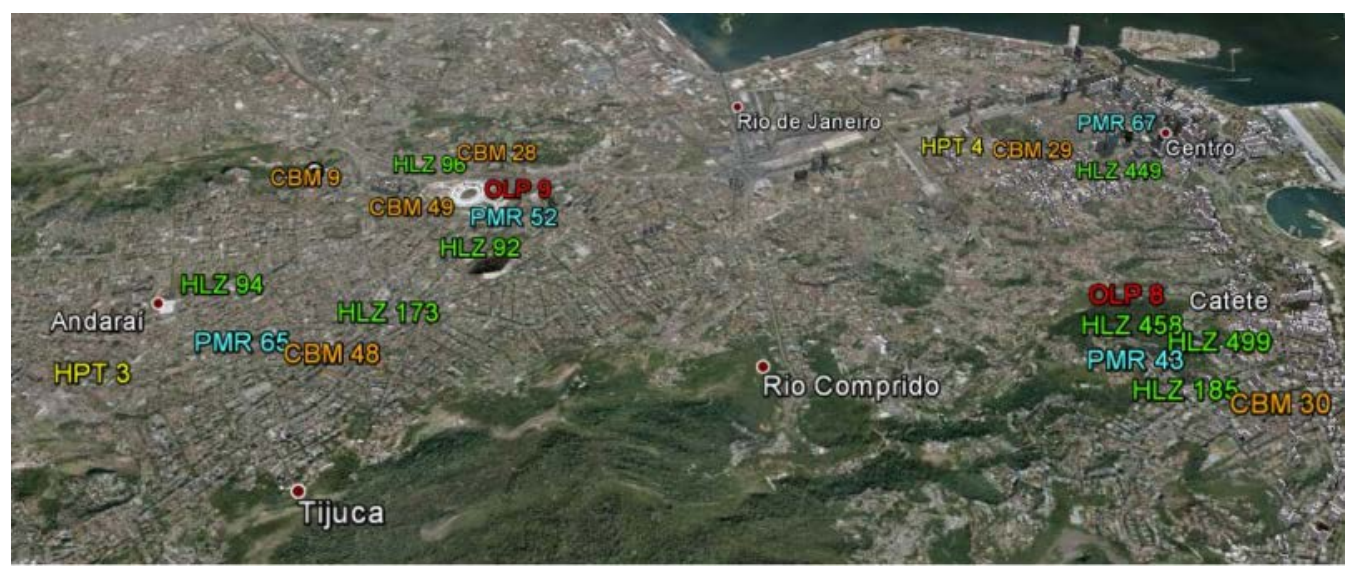

Figure 2: Satellite image obtained by plotting the four selected clusters in Google Earth ${ }^{\circledR}$. 
Figure 2 shows that the four clusters correspond to sets of points that are located in the following neighborhoods: Tijuca and Andarai (cluster 9), Maracanã (cluster 11), Downtown Rio de Janeiro (cluster 68) and Catete (cluster 44). Among the HLZs contained in the Tijuca and Andarai cluster, HLZ 173 was ranked the highest. In the Maracanã cluster, HLZ 96 was ranked the highest, and in the downtown Rio de Janeiro cluster, HLZ 449 was ranked the highest. HLZ 449 was located near the Central Headquarters of the Fire Department, the Souza Aguiar Municipal Hospital, the Military Police and a Civil Police Unit.

\section{CONCLUSIONS}

The motivation behind this work came from the need to have an alternative to ground transport for locomotion of tourists, citizens, authorities and athletes who will be in Rio de Janeiro for the Olympic Games and the World Cup. A integration based model, which allows allocating the HLZs considering points of public interest, was proposed for this very reason.

The strength of our work is the ability to deal with multiple criteria and model uncertainty in location planning for helicopter landing zones. The practicality demonstrated by this proposed method and the utility and clarity of the obtained results indicates that this method will contribute to the development of public policies that are aimed at streamlining existing aerial resources (helicopters) of agencies in the state of Rio de Janeiro. Thus, these agencies can better meet the health and safety demands of the population and actively contribute to the large sporting events that are predicted to occur in 2014 and 2016 in Brazil. In addition the application of this methodology to other Brazilian cities, is also of interest, for the reasons already mentioned.

In the future, studies that incorporate a method for considering the costs of the proposed method should be conducted regarding the transformation of the mapped HLZs into registered heliports, adapting them to technical standards.

\section{BIBLIOGRAPHIC REFERENCES}

[1] Agrawal, S., Raghavendra, N., Tiwari, M.K., Goyal, S.K. (2010). A hybrid Taguchiimmune approach to optimize an integrated supply chain design problem with multiple shipping. European Journal of Operation Research, 203: 95-106.

[2] Aikens, C.H. (1985). Facility location models for distribution planning. European Journal of Operational Research, 22: 263-279.

[3] Chen, Y. and Qu, L. (2006). Evaluating the selection of logistics centre location using fuzzy mcdm model based on entropy weight. Proceedings of the 6th World Congress on Intelligent Control and Automation. Dailan, China, June 21-23.

[4] Chi, S.C. and Kuo, R.J. (2001). Examination of the influence of fuzzy analytic hierarchy process in the development of an intelligent location selection support system of convenience store. IFSA World Congress and 20th NAFIPS International Conference. Joint 9th, Vol. 3, pp. 1312-1316. 
[5] Hamacher, H.W., Nickel, S. (1998). Classification of location models. Location Science, 6: 229-242.

[6] Lee, H.M. (1996). Group decision making using fuzzy sets theory for evaluating the rate of aggregative risk in software development. Fuzzy Sets and Systems, 80: 261-271.

[7] Lee, S.M., Green, G.I., Kim, C. (1981). A multiple criteria model for the locationallocation problem. Computers and Operations Research, 8: 1-8.

[8] Levine, A. (1984). A model for health projections using knowledgeable informants. World Health Statistics Quarterly, 37: 306-317.

[9] Luenberger, D.G. (1984). Introduction to Linear and Nonlinear Programming (2 ${ }^{\text {nd }}$ ed). Addison-Wesley.

[10] MacQueen, J. (1967). Some methods for classification and analysis of multivariate observations. In: Proceedings of the fifth Berkley Symposium on Mathematical Statistics and Probability. Berkley, CA. University of California Press.

[11] Narasimhan, R. (1979). A fuzzy subset characterization of a site-selection problem. Decision Sciences, 10: 618-628.

[12] Pill, J. (1971). The Delphi method: substance, context, a critique and an annotated bibliography. Socio-Economic Planning Sciences, 5: 57-71.

[13] Rio de Janeiro. Office of Public Safety. Military Police. GAM/PMERJ 2010-2016 Multi-year plan. [Rio de Janeiro]: Aerial and Maritime Group, [2009].

[14] Ross, G.T., Soland, R.M. (1980). A multicriteria approach to location of public facilities. European Journal of Operational Research 4: 307-321.

[15] Sun, H., Gao, Z., Wu, J. (2008). A bi-level programming model and solution algorithm for the location of logistics distribution centers. Applied Mathematical Modeling, 32: 610-616.

[16] Terano, T. (1992). Fuzzy Systems Theory and Its Application. San Diego: Academic Press.

[17] Tsou, K.W., Hung, Y.T. and Chang, Y.L. (2005). An accessibility-based integrated measure of relative spatial equity in urban public facilities. Cities, 22: 424-435.

[18] Wei, L., Zhen-gang, Z., and Xinpu, W. (2008). Application of multi-objects fuzzy comprehension evaluation in selecting location of coal-fired plant construction project. MMIT, Proceedings of the 2008 International Conference on Multimedia and Information Technology. Washington, USA, Dec 30-31.

[19] Zadeh, L. A. (1965). Fuzzy sets. Information and Control, 8: 338-353.

[20] Zadeh, L. A. (1975). The concept of a linguistic variable and its application to approximate reasoning. Information Sciences, 8: 199-249. 